\title{
Na fanfarra de Almáquio Dinis
}

Antonio Arnoni Prado

RESUMO: No presente artigo, analisa-se a produção do baiano Almáquio Dinis (1880-1937), crítico que escapa a qualquer juízo que se arrisque a explicá-lo. Trabalhou com uma imensa variedade de temas, vasculhando ângulos comuns a objetos inconciliáveis, que costumava desdobrar em livros simultâneos, como ocorreu com os esboços sobre a Preparação socialista do Brasil e com o ensaio sobre a Sociologia soviética, em 1934.

PALAVRAS-CHAVE: Pensamento brasileiro, crítica literária, Almáquio Dinis

ABSTRACT: The present paper analyzes the writings of Almáquio Dinis (18801937), a Brazilian critic whose work eludes the one who dares to explain it. He worked on a huge variety of themes, detecting perspectives common to irreconcilable objects, which emerged in simultaneous books, as in the case of the drafts of Preparação socialista do Brasil and in the essay Sociologia soviética from 1934.

KEYWORDS: Brazilian thought, literary criticism, Almáquio Dinis. 
Caso talvez único na crítica brasileira de inícios do século passado, o baiano Almáquio Dinis (1880-1937) é o tipo do crítico que escapa a qualquer juízo que se arrisque a explicá-lo. Não que os seus livros se afastem muito dos rígidos padrões da mentalidade "cientificista" que irradiou da chamada Escola do Recife, responsável, como se sabe, pelo dogmatismo extremo que cristalizou a vida intelectual brasileira de Tobias Barreto e Sílvio Romero para diante. É que em seus escritos são praticamente indiscerníveis os argumentos de que se vale para chegar a uma relação propriamente crítica com o objeto literário.

Filho de um farmacêutico, Almáquio foi professor de Filosofia Jurídica na Faculdade Livre de Direito da Bahia e um dos fundadores da Faculdade Teixeira de Freitas, de Niterói, chegando depois a catedrático de Direito Civil na Universidade do Rio de Janeiro. Mas não foi apenas como jurista que marcou a sua trajetória intelectual, apesar da prolixidade de seus escritos na área do Direito, bem como do gosto pessoal pelo ensaio filosófico e pelos estudos sociológicos e de criminologia, como revela sua extensa bibliografia.

Um de seus críticos nos lembra inclusive que ficou conhecido como o "Almanaque Dinis", dada a imensa variedade dos temas em que se metia, vasculhando ângulos comuns a objetos inconciliáveis, que costumava desdobrar em livros simultâneos, como ocorreu com os esboços sobre a Preparação socialista do Brasil e com o ensaio sobre a Sociologia soviética, em 1934. Através deles, aderiu ao marxismo e demonstrou afinidades com o ideário da Aliança Nacional Libertadora, em favor de cujos revoltosos teria interposto um recurso de habeas corpus, que o levou a ser preso por mais de uma vez, uma delas em sua própria casa, de onde teria saído de pijamas para um dos quartéis da cidade, por se ter recusado a trocar de roupa. Referindo-se ao episódio, um de seus bisnetos lembrou recentemente que, posto em liberdade, Almáquio fez questão de voltar a pé para casa, caminhando de pijamas pelas ruas do centro da cidade e levando atrás de si uma enorme multidão de ativistas, a quem ia detalhando a truculência de que fora vítima.

Foi assim que incomodou muita gente e ocupou largo espaço na imprensa de seu tempo, sendo quase sempre lembrada a "obsessão biológica e materialista" que teria inclusive levado o padre Leonel Franca a excluí-lo de sua História da filosofia, fazendo aumentar a fama de um Almáquio "pensador monista", entusiasmado com a filosofia de Haeckel, apesar de estar em Kant a sua confessada preferência.

O fato é que essa vocação desgovernada enveredou desde cedo para o jornalismo e as letras. Aos quinze anos, dirigia o jornal Tribuna Acadêmica, de apenas três núme- 
ros; aos dezessete já estava na secretaria de redação do Jornal de Notícias, da Bahia, no qual ficaria célebre por haver publicado, em francês, uma resenha sobre Les Sept Femmes de la Barbe Bleue et autres contes merveilleux, de Anatole France, por ocasião da visita do ilustre escritor ao Brasil em agosto de 1909.

"Era um imberbe ainda, rosto escanifrado, arredio, por temperamento, de rodas e côtéries" - nos diz Américo de Oliveira, para informar que, aos catorze anos, fazia versos românticos, aos dezoito compunha "artigos de ciência" e, aos vinte, já havia lançado uma revista escolástica, a Mercúrio, "com a qual chamou todas as atenções da contemporaneidade, que logo descobriu em Almáquio Dinis o escritor que se assinava Aquiles Donato", pseudônimo que alternava com os de Antônio Lupus, Gelis Dongalves e Zinido, entre outros. ${ }^{1}$

Foi nas páginas da Mercúrio, cuja tinta de impressão ele mudava de número para número, que surgiram suas primeiras poesias simbolistas, com destaque para o poemeto "Dona Urânia", uma espécie de "congraçamento de quatro mulheres vagas, para a criação de uma forma concreta". $\mathrm{E}$ foi com o mesmo ritmo vertiginoso que chegou, em 1911, a presidente de honra e um dos fundadores da malograda Academia Baiana de Letras, proferindo inclusive o discurso de abertura. E que, mais tarde, com o desaparecimento desta, assumiria a cadeira 37 da Academia da Bahia, fundada em 1917 para substituir a primeira, sem esquecer que depois se transferiu para a Academia Carioca, da qual seria, em 1934, o titular da cadeira de número 3, já com olhos voltados para "a glória suprema" de chegar um dia à Academia Brasileira de Letras.

Candidato à vaga de Euclides da Cunha, sabemos que acabou derrotado por Afrânio Peixoto, em rumoroso pleito que o levou inclusive a pedir a impugnação de Afrânio, sob a alegação de que este se inscrevera fora de prazo. Quem viveu o episódio sabe que não foi fácil aos imortais do Trianon livrar-se da presença de um Almáquio enfurecido pelos arredores da Academia, vociferando dias seguidos contra "o escândalo da derrocada moral lastimável", com todas as consequências que a decisão implicava. ${ }^{3}$

1. Oliveira, Américo de. Almáquio Dinis: um golpe de vista sobre a sua vida e a sua obra. Rio de Janeiro: Editora Brasileira Lux, 1924, p. 14.

2. Id., pp. 14-5.

3. Embora tendo recebido o apoio de autores como Sílvio Romero, Coelho Neto e Rui Barbosa, consta que o nome de Almáquio foi duas vezes recusado pela Academia Brasileira de Letras em razão de haver publicado o romance A carne de Jesus, no centro de cujo enredo imagina um relacionamento amoroso entre Jesus Cristo e Maria Madalena. Proibido e recolhido pelas autoridades, a pedido da igreja católica, 
A verdade é que, se não logrou "transpor os umbrais do silogeu", como ele mesmo lamentou certa vez a um de seus entusiasmados admiradores, jamais deixou de se portar como um legítimo acadêmico. Basta lembrar a pose com que exibia algumas das pragas mais visíveis da retórica afetada dos silogeus: a pretensão científica, o polemismo civilizador à Sílvio Romero e a argumentação enciclopédica. ${ }^{4}$

O leitor de A relatividade da crítica, por exemplo - e este é talvez um de seus livros menos tumultuados do ponto de vista metodológico - , há de se surpreender com o despropósito de suas suposições. Em primeiro lugar pela complexidade dos temas a que se atira, em especial dos estudos que pretendeu inaugurar no terreno da crítica, da teoria literária, da literatura comparada, da teoria dos gêneros, além da própria criação ficcional, que inclui romances, dramas, contos e crônicas. E depois pela veemência dos princípios que se propõe a adotar, ao dizer que seu livro pretende ser "um grito forte de alarme contra a inanidade e a inscícia (sic) nacional", incapaz, segundo ele, de reagir aos argumentos cansativos da crítica prolixa "dos Sainte-Beuve e dos Faguet", a quem sempre faltou - assegura - a objetividade que ele, Dinis, "lutava para introduzir na crítica", com a finalidade de mostrar que "um bom livro se evidencia pelo menor tempo exigido para causar a maior emoção".

o romance de Almáquio suscitou um rumoroso escândalo que levou o papa Pio XI a excomungá-lo, através do arcebispo da Bahia, D. Gerônymo Thomé da Silva, com a agravante de estender a punição canônica a três gerações de sua descendência. Foi tal a repercussão do livro no Brasil, que Carlos Drummond de Andrade, num dos poemas reminiscentes de Boitempo ("A livraria Alves"), recorda-se das impressões que lhe causara "o título sacrílego" do livro, numa tarde de domingo em que, adolescente, passeando na rua da Bahia, em Belo Horizonte, viu-o rutilando na vitrina e prometeu a si mesmo entrar um dia "naquele lugar de danação" para comprar "um livro mais terrível que o do Almáquio/ e nele me perder - e me encontrar". Cf. ANdrade, Carlos Drummond de. "Livraria Alves". In: Boitempo. Poesia e prosa. Rio de Janeiro: Nova Aguilar, 1992, p. 653.

4. De resto é ler a sua biografia para constatar que os acadêmicos do Trianon deixaram escapar um legítimo aspirante, cujo lugar não poderia ser outro senão a própria Academia. E isto não apenas pela celebração excessiva dos que insistiam em apresentá-lo como a um "autor de formação enciclopédica rara entre os seus contemporâneos", mas sobretudo pela valorização infundada do mérito dos mais de cem livros que publicou. Ver a propósito: As candidaturas de Almáquio Dinis e Wanderley Pinho à Academia Brasileira de Letras. Salvador: Academia de Letras da Bahia/ Assembleia Legislativa do Estado da Bahia, 1999.

5. DINIs, Almáquio. A relatividade da crítica. Rio de Janeiro: Papelaria Vênus, 1923, pp. 11-2. 
Assinale-se que tal pretensão científica vinha já de uns quinze, vinte anos passados, no âmbito de suas primeiras incursões literárias, se não quisermos remontar aos tempos da própria adolescência, quando, antes mesmo dos dezesseis anos, ensinava aos alunos do ginásio os fundamentos da História Natural, tema de que se valeu para uma conferência sobre "Teoria da formação da Terra", que ficaria na memória dos estudantes do Grêmio Evolução, um dos mais conceituados da Bahia daquela época. Por outro lado, não escapou a Afrânio Peixoto o ímpeto materialista com que Almáquio, nas páginas de $O$ eterno incesto (1902), por exemplo, investia contra os que ainda insistiam em doutrinar sob "o evangelismo casto de Tolstói”. Nas palavras de Afrânio, uma "aguçada curiosidade multiplicou os leitores do livro de Almáquio: a onda selvagem refluía vertiginosa e o livro ficaria, isolado como o rochedo que as águas teimosas não derrubam". 6

Mesmo os que conhecem aquela voragem de verdades científicas que Antonio Candido pôde desbastar, perplexo, em meio aos excessos com que Sílvio Romero se propunha a assumir "a reorganização do processo integral de crítica à cultura brasileira", mesmo esses não deixarão de espantar-se com as bazófias de Almáquio, ao citar Daniel Barthelot, Henri Bergson e Paul Painlevé para chegar a Albert Einstein e então concluir que a melhor crítica "é a que estabelece, com segurança, aquele minuto mínimo de tempo gasto para ser produzida a máxima emoção possível".

Claro que, para o leitor, nada aparece dos experimentos de Barthelot, assim como das teorias matemáticas de Painlevé, muito à deriva ao lado das figurações abstratas do tempo desenvolvidas por Bergson, igualmente citado sem qualquer referência pontual. Mas ir a Einstein para nos dizer, por exemplo, que este seria um grande crítico se a sua teoria da relatividade "não tivesse limitado a sua compreensão ao sentido visual dos homens", como afirma Almáquio às páginas 12 e 13, soa como atrevimento de adivinho, particularmente se pensarmos no nonsense da conclusão, em que pretende demonstrar nada menos que a diferença entre o livro escrito e o livro lido corresponde à "diferença de tempo entre dois comboios paralelos, dotados de semelhante velocidade e que demandam ao mesmo ponto".

Não, leitor: não se trata de galhofa ou trapaça: ler os livros de Almáquio Dinis é arriscar-se a conviver com alguém disposto a garantir que a imaginação literária

\footnotetext{
6. oliveira, Américo de, op. cit., pp. 17-8.

7. DINIS, Almáquio, op. cit., p. 12.

8. Id., ibid., p. 13.
} 
pode ser pesada, medida, descrita e meticulosamente classificada como experimento demonstrável no âmbito das "ciências exatas", cujas teorias, nele, predominam sobre os estudos de texto e de estilo. ${ }^{9}$ É mergulhar na experiência de alguém que - a crer nas indicações de seus contemporâneos - se correspondia regularmente com vários entendidos na teoria de Einstein, gente como Carlo Bocelli, Jean Villey, Leon Block, Ernest Seillière, Émile Magne, Tulio Levi Civita, entre outros.

Basta dizer que, ao contrário de Sílvio Romero e os críticos naturalistas, por exemplo, que, antes de ingressarem no texto literário, faziam longas e doutas digressões sobre sociologia, climatologia, antropologia, biologia, jurisprudência e etnologia, bem ao contrário deles, Almáquio dilui o texto na colagem das citações científicas em alemão, em inglês, em francês e até mesmo em latim, sem qualquer interesse em valer-se da fortuna crítica dos autores que "analisa", nem tampouco dos estudos sobre as tendências estéticas do período ou mesmo sobre os avanços da crítica e da historiografia.

Uma amostra dessa extravagância intelectual está na forma como ele, partindo de um verbete de D’Alambert na Enciclopédie - que ajusta a seu modo às conclusões da teoria da relatividade de Einstein —, chega, por exemplo, aos fundamentos literários dos contos que Coelho Neto reuniu em Vesperal. Dito assim, parece troça, coisa de vidente ou maluco, mas também coisa que poderia ser de um leitor "inspirado" possivelmente "um gênio" para alguns resenhistas do nosso tempo - alguém que, ao invés de propor esse malabarismo crítico, escolhesse o ângulo da ficção ou do relatoflagrante para, de algum modo, aludir ao incerto da alegoria e do fragmento, tão abertos às mutações do século que então se abria.

Mas não é assim para Almáquio. Ao contrário: "em Vesperal - nos diz ele encontra-se uma razão plausível com que se demonstra a quarta dimensão, verdadeiramente composta do espaço-tempo", categoria que ele procura explicar valendo-se da concepção de "tempo local" (1904), do físico Hendrik Lorentz, decisiva — segundo

9. E isto a tal ponto que, para Almáquio, a moral do literato não se confunde com a moral do cientista. Segundo ele, há em todo escritor duas morais: "uma que aparece em público, em seus livros de literatura ou de arte, respeitando os princípios da crença literária”; e outra moral é a moral do indivíduo, enquanto "cidadão e homem escravo das leis da sociedade e da família suas contemporâneas". Tais conceitos, nos diz ele que "não alcançam os homens de ciência, a quem só interessa a grande verdade, só o que realmente possa interessar à humanidade". Isso explica que, para ele, "no choque das duas morais - a do cientista e a do literato - prevalecerá como pura e verdadeira a do cientista". Cf. Zoilos e estetas (figuras literárias). Porto: Chardron, 1908, pp. 9-10 e p. 16. 
os especialistas - para a teoria da relatividade de Einstein (1905), que o matemático Hermann Minkowski, citado por ele [Raum und Zeit, 1908], afirmaria "ser melhor entendida (sic) num espaço-tempo de quatro dimensões", onde tempo e espaço deixam de ser categorias separadas.

Pois é desse labirinto abstrato das formulações físico-matemáticas ["ninguém jamais viu um lugar de outro modo, senão em um certo tempo, nem um tempo de outro modo, senão em um certo lugar"], ${ }^{10}$ que Almáquio, louvado em Minkowski, transporta mecanicamente para a prosa de Coelho Neto a observação de que Vesperal é um índice "não do tempo em si, mas do tempo em combinação com o espaço, porque o tempo em si e o espaço em si desapareceram do domínio das realidades objetivas, sendo única realidade objetiva a combinação espaço-tempo, que é o meio em que sucedem os fenômenos".

O que pretende nos dizer é que a "certeza" teórica do discurso científico citado em alemão se converte em juízo crítico com o qual o estilo retórico de Coelho Neto parece enfim haver encontrado um leitor à sua altura. Tudo como gostavam os intelectuais da época. A diferença é que, na apreciação do texto, a verdade propriamente literária não aparece, as palavras, as frases e os períodos não se articulam com a sensibilidade empolada da inventio, sem qualquer interesse em chegar às imagens, aos ritmos e pulsões da escrita encaroçada do velho literato de A conquista.

Tudo porque, nas mãos de Almáquio, juízo crítico é transcrição mecânica de conceitos bem ou mal copiados aos manuais de ciência aplicada, como o atesta o trecho em que ele afirma que "a demonstração que se encontra no livro de Neto é o testemunho da verdade de que a duração, como queria D’Alambert, é uma quarta dimensão, porque o tempo situado em Vesperal, por exemplo, possui as mesmas propriedades que as coordenadas espaciais: a continuidade, a infinidade nos dois sentidos e a variação uniforme"."

Longe de nós a intenção de prosseguir nos "princípios" dessa vertigem intelectual com que Almáquio investe contra o ofício da crítica, mas apenas a de confirmar que eles de fato existem. Primeiro no modo como concebe a diferença entre o crítico e o leitor, reduzindo-os a "dois comboios que investem paralelamente sobre um dado ponto",

10. Frase transcrita por Almáquio de uma das conferências de Hermann Minkowski, um ano antes de sua morte, enfeixadas no já citado Raum und Zeit.

11. Id., p. 89. 
constituindo-se a crítica na diferença mínima entre ambos. E depois na maneira como qualifica a positividade da análise, para ele tanto mais arguta quanto mais "assentada nos princípios verdadeiros da relatividade do tempo".

O estranho nisso tudo é que, em meio à abstração desmedida, às vezes despontam alguns lampejos que parecem induzir à concatenação do argumento, como no caso da advertência de que "não é dado que se critique aquilo que se não sabe enunciar"; ou ainda da distinção de que a crítica "é uma arte de conhecer mais complexa do que a arte de representar"."

Mas são apenas lampejos, pois os juízos não se complementam, toldados pelo destempero. Para Almáquio, a maioria dos críticos não é capaz de exercer a crítica justamente por ignorar "a obra monumental de Albert Einstein", sem a qual não estão preparados para enunciar o objeto que pretendem criticar.

Porém há mais. Um terceiro princípio sustenta que a crítica é "a diferença que sobressai entre o livro escrito e o livro lido", com a ressalva metodológica de que "onde essa diferença não se verifica, a crítica é irrealizável". Não que a perfeição da obra transcenda o alcance da crítica. É que, para Almáquio - como no exemplo da diferença de tempo entre os dois comboios paralelos -, "a crítica e a obra de arte não se ajustam senão efemeramente; e se é nesse ponto que uma se pronuncia sobre a outra, nada há que se sinta diferentemente". ${ }^{13}$ Quer dizer: se um bom livro se impõe pelo menor tempo exigido para causar a maior emoção, a crítica só se realiza quando o tempo da emoção do artista e o da emoção do crítico se mostrarem autônomos e complementares nessa convergência.

É inútil pretender saber que elementos da análise lhe permitem expressar tamanha convicção. Antes mesmo que pensemos nos recursos de teoria e hermenêutica literária, Almáquio fecha a incursão estética - se concedermos que existe uma para voltar ao labirinto das relatividades. Para ele, os elementos que permitem esse grau de certeza assentam, todos, "sobre fórmulas novas de gravitação", que transcreve a partir da equação de Albert Einstein, incorporada com a maior naturalidade, sem a menor hesitação:

$$
d s 2=d t_{2}(1-a / r)-d t h 2+\sin t h d f_{2}-d r_{2} / I-a / r
$$

\footnotetext{
12. Id., p. 94.

13. Id., pp. 96-7.
} 
"onde $d s$ - garante ele - é o elemento de geodesia percorrido no Universo por um ponto gravitante $r$ e designa o raio vetor desse ponto gravitante $r$ em relação com o centro maciço, sendo o $a$ um comprimento proporcional a essa massa, que, no caso do sol, é igual a pouco mais ou menos três quilômetros".14

O leitor por certo haverá de perguntar, intrigado: $\mathrm{E}$ a prosa de Coelho Neto, o que ganha com isso tudo? Almáquio é implacável: se um bom livro se revela no menor tempo exigido para causar a maior emoção, é claro que, não havendo essa diferença, a crítica não se realizou, tendo coincidido a emoção do autor com a do crítico. "Em aparência isto é possível", nos diz ele. Mas adverte que isto representa

um dos maiores absurdos pelo princípio de que dois fatos não podem, ao mesmo tempo, ocupar o mesmo lugar no espaço [...]. Se assim é, que se registre essa coincidência, no momento mesmo em que ela aparentemente se revela, antes, pois, que as diferenças comecem a revelar-se e cheguem a um extremo tal que os dois comboios de marchas paralelas se percam totalmente de vista. ${ }^{15}$

Não haveria mais o que dizer desse pacote de certezas concebido em 1923, não fossem os pressupostos críticos do ensaio Da estética em literatura comparada, publicado no Rio de Janeiro, em 1911, pela casa Garnier, em cuja "Prefação" Almáquio - já então presidente honorário da Academia Baiana de Letras - se propõe justamente a elucidar a cientificidade do método que utilizou para explicar a natureza da literatura comparada.

O dado interessante é que, na "Prefação", que ele confessa haver composto "em meio a outros volumes" - mais de dez, escritos simultaneamente - , delineia-se um verdadeiro "programa científico" voltado, entre outros, para os estudos sobre a Genesis e evolução do sentimento estético, sobre As teorias do belo originadas em Ruskin, bem como sobre Os clássicos na literatura moderna e O princípio do belo na evolução do romance brasileiro.

Em todos eles, segundo Almáquio, a grande meta é chegar a três objetivos específicos: "O conhecimento pleno dos gêneros e processos literários dos tempos modernos", que ele chama de aspectos extrínsecos; "o estudo da colocação definitiva da estética no

14. Id., p. 96.

15. Id., pp. $97-8$. 
quadro dos valores científicos", segundo ele os aspectos intrínsecos; e a afirmação da existência e das causas de uma "fase literária de transição" para um período individualista, na qual "a estética faça arte por seu próprio esforço, sem o prestígio dos códigos escolásticos [...]” ${ }^{16}$

Por acreditar que o país atravessava "um período de grande confusão escolástica", Almáquio alertava para a urgência de nos prepararmos para a fase do "futuro individualista da arte", paralela à nova etapa do que considerava "o futuro individualista das sociedades humanas", previsto por John Ruskin quando se referiu - nos diz ele - a uma "vida social perfeita" em que a beleza e a verdade caminhariam juntas. ${ }^{17}$

Ao descartar de saída influências como as de Max Nordau, Maurice Le Blond ou Saint-Georges Bouhélier, teóricos - como sabemos - interessados em exaltar "o advento de uma humanidade superior em força, em grandeza e em beleza", Almáquio justamente se propõe a afastar-se desse ideário "de desilusões movidas pela pompa do escândalo".

Para ele, a estética devia ser tratada como "uma ciência de método próprio, que recebe os influxos das ciências naturais como ciência social que é" e que transcende aos próprios ideais de John Ruskin, à medida que enfeixa em sua própria essência tudo aquilo que "no menor prazo de tempo possível desperte o maior número de ideias".

$\mathrm{Na}$ verdade, o que ele pretende, ao enfatizar na beleza a única fonte dos valores estéticos, é deslocar esses valores para a arte e a crítica que os determina como "dois raios luminosos da grande estrela" que se chama estética. ${ }^{18} \mathrm{Ou}$ seja, de um lado, a beleza a serviço da arte; e, de outro, a verdade a serviço da crítica. Daí que, para Almáquio, só há sentido em falar-se de estética, levando em conta que "a arte é o aproveitamento da beleza sob um dado critério psíquico"; e que a crítica "é um reconhecimento da verdade no aproveitamento da beleza".19

Com isto intenta rechaçar as teses dos "diversos credos" de seu tempo, de Zola a Arno Holz (tão caro a João Ribeiro), passando por Taine, Sainte-Beuve, Sílvio Romero, José Veríssimo e o próprio João Ribeiro, entre outros. Ao contrário de todos eles, sus-

\footnotetext{
16. DINIS, Almáquio. "Prefação". Da estética na literatura comparada. Rio de Janeiro: H. Garnier, 1911, pp. X-XI.

17. Id., p. 6.

18. Id., pp. 6-17 e passim.

19. Id., p. 17.
} 
tenta que a crítica "não é a cultura apaixonada de um ideal aparecido numa época de desilusões" de um momento crítico da literatura francesa, e sim "a produção literária que visa a um fim e o preenche" e cujo valor precisa ser determinado "em relação com o tempo e o meio em que ele se formou".

Mas a partir daqui o que parecia apontar para um sinal de ruptura com o naturalismo positivista - que impregnava toda a crítica do período - logo muda de curso para recair em cheio num "cientismo" descritivo dos mais desbragados, que chega inclusive a registrar "o sentimento do belo se formando no fronema humano por informações partidas do sensorium", cujo mecanismo Almáquio faz remontar aos "nervos fronetais" encarregados de produzir as condições físico-químicas indispensáveis à fruição do fato belo. ${ }^{20}$

Por esse caminho, não apenas reincorpora a perspectiva retórica dos critérios que tanto censurou no "psicologismo" de Taine e no "sociologismo" de Sílvio Romero, por exemplo, como também recompõe o horizonte crítico destes últimos, ao rearticular a emoção humana com "o estado de cultura do momento", para em seguida afirmar que “o sentimento estético não é apenas uma função psíquica do homem, mas sim 'uma ordem de sensações despertadas pelo convívio social"'.

Como ler de outro modo a sua explicação de que a estética, enquanto ciência especial, se vale dos processos das ciências naturais com a finalidade de estimular "o progresso do belo nas ações humanas" e assim aprimorar o seu "espelhamento nas artes respectivas"? ${ }^{22}$

O diabo é que, novamente, o balaio transborda e o argumento do crítico, até então meticuloso e carregado de erudição disciplinar, perde equilíbrio e se desintegra ao tentar ingressar nas águas mais fundas da criação literária.

Não que o mergulho comece mal. "O mundo" - nos diz ele de repente, do coração para a pena, como quem fosse afinal aprofundar a leitura - "o mundo é o repositório calmo da maior poesia, porque é o acervo inédito de todas as belezas. Em cada trecho há um poema ou um canto de arte”. E emenda:

\footnotetext{
20. Id., p. 25.

21. Id., pp. 28-9.

22. Id., ibid.
} 
nos seus movimentos mais sutis lega ao homem a razão de uma longa produção estética. A noite é negra, o céu sem luzes, o mar proceloso: o raio desce e inspira miríades de criações sobre a simples beleza nua que desvendou. O dia é brilhante, o sol triunfador, a seara alegre e povoada de asas multicores: a nuvem pesada encobre o grande astro e desperta o coração do triste para a compreensão da grande beleza que é a sombra num dia de grande luz. ${ }^{23}$

A notação vai num crescendo até o momento em que Almáquio se lembra do salto vertiginoso com que Mallarmé define a poesia "num mundo dentro do próprio mundo", para em seguida retomar os "achados" de Edgar Allan Poe no ensaio sobre "O princípio poético", que ele estende para os experimentos literários de Gabriele d’Anunzzio, tudo para enfatizar que a primeira qualidade da poesia é "a emoção do leitor", ficando para o poeta não mais a tarefa "de alongar a beleza natural", mas sim de "concentrá-la em um grupo reduzido de versos, de forma que a maior beleza do universo fique contida num acervo mínimo de imagens" ${ }^{24}$ - argumenta.

Mas o anúncio fica por aí, sem qualquer referência mais concreta à obra dos autores citados, nem tampouco à análise dos pontos interessantes que o argumento parecia conter. As observações outra vez mudam o seu curso e obscurecem, para cair de novo nas virtudes da "policromia" do Fabulário de Coelho Neto como fator enriquecedor da tradição moderna do estilo clássico (p. 109). Isto quando não recuam para o recorte realista da função da personagem, como faz Almáquio ao defender um argumento de Eça de Queirós descartando - em carta a Ramalho Ortigão - a necessidade de aprofundar a individualidade de seus personagens num país, como Portugal, em que, diferentemente de Paris ou Londres, nos termos de Eça, só havia um tipo de homem, "que é sempre o mesmo ou sob a forma de $d a n d y$, ou de padre, ou d'amanuense ou de capitão: é o homem indeciso, débil, sentimental, bondoso, palrador, deixa-te ir, sem mola de caráter ou de inteligência que resista contra as circunstâncias".25

Dá-se o mesmo em relação às observações inovadoras que o autor acrescenta ao conceito de conto, já então, para ele "uma página de arte em que colaboram, por síntese, a imaginação, a fluência da linguagem e a observação, por igual, do mundo

\footnotetext{
23. Id., p. 53 .

24. Id., p. 54 .

25. Id., p 114.
} 
real" (p. 121). E mais: num contexto que aponta inclusive para a necessidade de uma teoria do conto estabelecida em "função sintética da arte", Almáquio alude à urgência de levar em conta a condensação das imagens "ao menor número possível”, de modo a fazer crescer a singularidade do gênero "na razão direta de sua diminuição". Ou seja: além de propor o que denomina de "morfologia intrínseca" do conto, Almáquio parece adiantar os pressupostos de uma análise inovadora, ao vincular a estrutura do gênero ao processo do que ele chama de "redução de um assunto à continência numérica das expressões, das palavras e das frases". ${ }^{26}$

Daí a razão de haver discordado de Araripe Júnior, quando este, ao distinguir o conto do romance, afirmou que no primeiro "os fatos filiam-se e percorrem uma direção linear", ao passo que, no segundo, eles se apresentam "no tempo e no espaço, reagindo uns sobre os outros e constituindo uma trama mais ou menos complicada". É que, para Almáquio, não havia sentido em propor para o conto, como faz Araripe, uma perspectiva do "pretérito" em contraposição à "atualidade" do romance com base na separação dos dois gêneros a partir da oposição entre o narrativo e o figurativo. Quer dizer: "não bastam, a seu ver, as qualidades de síntese e monocronia para uma obra ser classificada de conto", dado que "sintético e monocrônico é também o argumento de um poema, para não ir mais longe", conclui ele, ao afirmar que "nem o conto é linear, nem o romance tem a especificidade de restringir-se ao tempo e ao espaço". ${ }^{27}$

São ideias interessantes que poderiam apontar para um encaminhamento crítico construtivo, não fossem as descaídas de praxe: além de complicar a linguagem, Almáquio parece esgotar o gênero do conto nas soluções do Jardim das confidências, de Coelho Neto, e pior: acaba enleado no critério das classificações mais esquemáticas, resumindo o universo do gênero a cinco tipos fundamentais (o conto provinciano, o nacionalista, o atualista, o rememorativo e o lendário), que ele exemplifica a partir de autores tão inexpressivos quanto Nelson de Sena, Portugal da Silva, Lindolfo Rocha, Carmen Dolores, esta por sinal "superior ao contista Sílvio Romero", autores sobre os quais paira, no centro de suas preferências, a figura isolada de Coelho Neto, a quem atribui "algumas produções dignas de comparação com as mais belas do Sr. Anatole France". ${ }^{28}$

\footnotetext{
26. Id., pp. 122 ss.

27. Id., pp. 124 ss.

28. Id., p. 140.
} 
É assim que porá a perder a conquista dos três objetivos específicos que definiu como meta principal de sua "Prefação", pois, a rigor, nem logrou revelar conhecimento pleno dos gêneros e processos literários dos tempos modernos; nem desenvolveu o prometido "estudo da colocação definitiva da estética no quadro dos valores científicos"; nem tampouco demonstrou a existência de uma "fase literária de transição para um período individualista", do qual a estética fizesse parte "por seu próprio esforço, sem o prestígio dos códigos escolásticos [...]”.

É verdade que deixou pelo caminho algumas aberturas que destoam do contrassenso, entre elas a de que a crítica, quando exercida para definir belezas, é uma atividade estética que não exclui a função social do crítico, cujo trabalho - segundo Almáquio - não pertence ao campo da filosofia da arte, e sim ao da "avaliação racional e erudita dos valores concretizados nas obras humanas", sempre levando em conta que "os meios da arte correspondem aos seus processos". Assim entendia, por considerar que à arte "simbólica" devesse corresponder uma "crítica simbólica", do mesmo modo que a uma arte "de expressão direta" corresponderia uma crítica "de expressão direta", daí resultando, para o núcleo da análise, a importância das relações entre "o gosto e as fantasias" do escritor e a "forma" com que esses sentimentos, ao se converterem em arte, a um tempo influem e sofrem influência dos "sentimentos e qualidades individuais" do crítico. ${ }^{29}$

Mas - ainda aqui - como não poderia deixar de ser, os conceitos se embaralham e logo nos vemos frente às classificações generalizantes dos passos anteriores. $\mathrm{E}$ o crítico, que parecia encaminhar-se para o interior de um processo hermenêutico, de repente se vê repartido em brigadas voluntariosas de intérpretes dos sentimentos, dividindo-se em "hedonistas", "otimistas", "pessimistas", ao lado dos críticos "de sentimento" e "de ficção".

O que vem depois - como o leitor pode imaginar - é uma avaliação meramente classificatória desses intérpretes aleatórios. José Veríssimo, por exemplo, chamado por ele de "o crítico pessimista das nossas letras" (p. 288), sendo um "crítico de sentimento", é também um crítico "eminentemente social", que teria tudo para igualar-se ao pessimismo de Giacomo Leopardi, não fosse - nos diz Almáquio - "aquele modus judicandi próprio do estagio cultural dos brasileiros". ${ }^{30}$

29. Id., p. 286.

30. Leopardi, para Almáquio, "julgava o mundo segundo o seu temperamento", e, como em Veríssimo, suas desafeições cresciam "em progressão geométrica em relação ao bem estar da consciência em que o 
Mas, se é assim em relação a Leopardi, o pessimismo de Veríssimo supera, a seu ver, o de Sílvio Romero, cujo cientificismo crítico, segundo ele, "modela a crítica pelo fim, que é o da ciência arranjada ao sabor dos tempos da prioridade dos seus estudos e de Tobias Barreto", o que faz de Sílvio "um pessimista de ficção, se não de ocasião". ${ }^{31}$

O fato, no entanto, é que a partir daqui o fecho do livro se converte numa espécie de acerto de contas com o próprio José Veríssimo, cuja crítica representa para Almáquio (tão maltratado por ele) a definição dos valores estéticos "pela necessidade de maior ou menor exaltação da pessoa do próprio crítico", já que para ele, em Veríssimo, o julgamento de uma obra partia invariavelmente de um único termo de comparação, dado por sua própria obra (p. 293). Daí a razão para que Veríssimo, na opinião de Almáquio, devesse ser incluído entre aqueles críticos que - na expressão de um autor francês desconhecido - "não deixarão de encher os hospitais e os gabinetes dos alienistas" por tudo o que representam, nos diz ele, "as suas avaliações críticas odientas, misantrópicas, niilistas e equívocas".32

O próprio João Ribeiro não ficaria sem resposta. Tanto assim que, no final dessas observações, Almáquio aproveita para retomar algumas "verdades" da crítica da época, como, por exemplo, as que João Ribeiro sustenta em suas Páginas de estética (1905), ao afirmar que não tínhamos uma literatura nacional porque justamente nos faltava um caráter nacional, herdeiros que somos da civilização portuguesa. Em Almáquio, a ideia retorna, mas de outra perspectiva, muito mais abrangente. Diz-nos ele que se não temos uma literatura nacional, temos em compensação uma época de transição "em que a literatura que herdamos de Portugal entra em gestação para, por meio de um renovamento, ser a literatura de nosso país", abrindo-se, aqui, para "o estudo da evolução estética do Brasil". Para ele, enquanto não se concretizarem as bases desse estudo, "será impossível escrever a história da literatura nacional", a despeito de todos os esforços de Sílvio Romero, de cuja História Almáquio discorda, "muito embora servida por um método sociológico".33 Ou seja: não havia ainda uma história da literatura brasileira,

autor se coloca". Para ambos - ele emenda - "o mal não é um alvitre, mas é um sentimento, e só é mau o que verdadeiramente é assim". Diz isso, entretanto, ressalvando o fato de que não cabe em Veríssimo "a universalidade do espírito do outro". Id., p. 292.

31. Id., pp. 292-293.

32. Id., p. 294.

33. Id., p. 326. 
porque o sentimento estético brasileiro não tinha uma história, "apenas uma evolução ontogenética", nos diz ele. O dado novo, aqui, está na crença - inovadora para a época - de que, mesmo em fase embrionária, a evolução estética do Brasil já era "uma evolução que se gerava demoradamente", feito um organismo distinto, a partir do qual "a literatura brasileira iniciará a sua história". ${ }^{34}$

A par dessas reflexões positivas, registre-se ainda, no final do livro, a obsessão pelo desagravo que marca os brios ofendidos do nosso crítico. Um exemplo é a transcrição, nos "Apêndices", de um trecho da carta com que José Veríssimo agradece ao autor a remessa do volume Da estética na literatura comparada. Nela, o crítico paraense discorda da generosidade de Almáquio, que inclui o seu nome ao lado de Teófilo Braga e Max Nordau na dedicatória. "Uma generosidade - escreve Veríssimo - que me parece excessiva”. O que, entretanto, está em jogo é a afirmação subsequente, em que Veríssimo considera o trabalho de Dinis, "um livro sério, meditado, e de certo modo interessante [...] com unidade, inspiração, estudo". ${ }^{35}$

A trégua, contudo, é apenas aparente, se nos lembrarmos da autêntica opção pelo confronto que Almáquio acabara de definir poucos meses antes, ao dar a público os depoimentos enfeixados em Meus ódios e meus afetos, em que faz uma espécie de arranjo entre as "virtudes" de suas convicções críticas e os "equívocos" da crítica de seu tempo, no Brasil e fora dele. ${ }^{36}$

Impressionante, pelo traço corrosivo das imagens, é o breve panorama com que traça, ali, um diagnóstico dos males que a seu ver "infestavam o ambiente da nossa crítica”. O capítulo que dedica a João Ribeiro, por exemplo, serve-lhe de pretexto para demolir o contexto inteiro, que se abre com a referência a uns "seis ou oito interessantíssimos casos de gabolice e enfezamento psíquico. Deles, uns, por incompetentes, querem flanar em alturas vertiginosas, de onde vivem a cair em esborrachamentos consecutivos", como José Veríssimo e Mário de Alencar, por exemplo; "outros, verdadeiramente nulos, não se compreendem em sua própria nulidade, e fingem-se de imortalizados, quando não são mais do que pedaços de carne, balofos e estúpidos, em vias de putrefação, como Felinto de Almeida"; "e terceiros, - acrescenta - estultos, parvos, ridículos, envoltos em capas de prodígios, são espectros de racionais, com o infortúnio de nunca se terem

34. Id., ibid.

35. Id., p. 347 .

36. DINIs, Almáquio. Meus ódios e meus afetos. São Paulo: Monteiro Lobato \& Cia., 1922, p. 13. 
visto antes num espelho. São os Joões Ribeiros, - arremata - escritores de cangalhas, em cujos açafates, como punhados de gramíneas, carregam pacotes empoeirados de Fabordões, de Páginas de estética e de Crepúsculos dos deuses". ${ }^{37}$

Aqui, a rudeza do ataque tem um alvo deliberado: os comentários que João Ribeiro publicou no Almanaque Garnier (uma "publicação para vadios", nos termos de Almáquio) sobre os poemas de Jackson de Figueiredo (Zíngaros, 1910), destacando a certa altura que o livro era prefaciado "pelo impagável crítico Almáquio Dinis, que só tem uma razão para apadrinhá-lo - dizia Ribeiro - e é ser um homem de jornal e de espantar meninos com as suas pachouchadas folhetinescas de crítica científica, orientação nova e outras baboseiras, já de cabelos brancos, a estas horas talvez mesmo carecas de todo". ${ }^{38}$

A resposta de Almáquio é algo mais que apenas retaliação. Referindo-se aos livros de João Ribeiro, ele afirma que irá, "bater de rijo sobre o costado mestiço do pregoeiro acadêmico, até desancar a alimária que vive a apodrecer sobre a poltrona de Pedro Luís". Mais ainda: depois de afirmar que Crepúsculo dos deuses não passava de "um livro de autores alemães defraudados por João Ribeiro", diz Almáquio que Páginas de estética é recheada pela "linguagem complicada, o emaranhado dos argumentos, a sutileza dos conceitos de filosofia, a indigesta saxomania (sic) das citações", produto de um espírito inconsciente que, segundo ele, "não mede o seu senso, nem pesa os seus conceitos, [de tal modo que] escrevendo no seu Almanaque, fê-lo para poder criticar-me. Não conseguiu fazê-lo como queria, porque nem jeito, nem arte lhe deu a natureza para trabalho de tanta monta". 39

Na avaliação desse contexto, uma de suas afirmações mais pontuais é a de que a crítica, como parte da estética, só raramente se manifesta sobre o belo natural. Ao contrário: cabe a ela julgar o belo artístico, "dentro das condições científicas desse fato esplêndido, que é a correspondência exata entre a emotividade e a compreensão sensorial do artista”. Se em relação a esta, a função da análise é, para Almáquio, “proceder para chegar a um

37. Id., p. 151.

38. Id., p. 155.

39. Id., pp. 157-69. 
fim [e assim] caracterizar o fato diferenciado", o que agora lhe interessa sublinhar é a ideia de que o crítico só será reconhecido funcionalmente como um averiguador dos valores estéticos quando, "diferenciados os fatos do belo, lograr situá-los no quadro dos valores respectivos".

Ressalta, no entanto, duas formas de crítica a partir das quais pretende avaliar o panorama da crítica brasileira. A primeira é a crítica descritiva - para ele um sintoma negativo que localiza sobretudo dentro dos limites estreitos do nosso jornalismo pródiga, a seu ver, em "ajuizar pelo lado mau" tudo quanto lhe cabe avaliar. A segunda é o que chama de crítica integral, manifestação intelectual construtiva que "descobre as formas sutis da beleza em todas as obras de arte, elevando [...] valores que não eram tachados como tais, e situando-os, com os seus verdadeiros expoentes, nos pontos certos do quadro que lhes é próprio".40

Diante de tais recursos, caem por terra, segundo ele, teses de críticos como Hennequin, Taine, Brunetière e La Harpe, todos eles - nos termos de Almáquio "derrubados pelas teorias das integrações estéticas", que vieram para substituir, entre outros, as ideias de um Sílvio Romero, um Miguel Mello, um Alcides Maia, e até mesmo o humor crítico de Machado de Assis.

A grande questão que se colocava para ele era a de não haver ainda "nomes definitivos" que se houvessem imposto ao novo panorama que então se desenhava, principalmente em razão do nosso atraso. "O desconhecimento da ciência alemã - afirmava - tem sido a causa imediata do retardamento dos nossos processos críticos", muito distantes ainda, a seu ver, das intervenções de um Charles Lalo na França, para ele um dos raros críticos que "quebravam a monotonia dos julgamentos aposteorísticos (sic) até então vitoriosos". Curioso é que ele se inclui a si mesmo ao lado de Lalo, ao nos explicar que "este autor - como fiz eu no Da estética em literatura comparada em 1911 - , deduzindo da filosofia estética dos alemães a diferença capital da crítica, fê-la grandiosamente diversa, como um processo de verdadeira ciência abstrata, que é, das mais poderosas no poder de abstração, quando se incumbe de diferenciar e de integrar valores estéticos".41

$\mathrm{Na}$ essência, Almáquio quer dizer que o alvo central do crítico é a "delimitação do belo nos fatos que caem sob sua apreciação", embora acredite que esta tarefa só se

40. Id., ibid.

41. Id., p. 14. 
completa quando, reconhecida "a espécie valiosa" dos fatos estéticos, ele conseguir integrá-los no "sítio próprio do quadro correspondente, seja qual for a transformação dos valores que neles se perpetre". Distante do pessimismo dos "tamanqueiros da crítica" e dos "mercadores de apodos", que é como denomina a crítica de José Veríssimo e seus seguidores, a verdadeira "função sociológica" do crítico moderno só será exercida, a seu ver, quando este souber "apreçar, avaliar e mostrar a relação entre a beleza objetivamente sentida e o interesse atual dos homens", visto que o "regime das obras-primas", enquanto "privilégio das genialidades", foi há muito tempo destronado pelo "sentimentalismo humano", ele explica. ${ }^{42}$

Essa tarefa - acrescenta - nem de longe pode ser confundida com a crítica produzida nos jornais, em cujo espírito maldizente e superficial a análise nem "diferencia" nem "integraliza”. ${ }_{43}$ "Todo livro - nos diz Almáquio - tem um valor, e não é para o negar que o leio. É para destacar que exerço, como posso e entendo, a função da crítica". E emenda: na leitura de um livro, "há sempre uma página, se não um trecho ou, pelo menos, uma pequena frase a representar um dos valores apreçados pela cultura humana”. Frente a eles, não cabe fazer como o leigo, que tende a passar ao largo: só o bom crítico é capaz, segundo ele, de perceber que neles pode estar escondido um "cristal luminoso". Daí o caráter filosófico que atribui à crítica, inspirado em Souriau, Lalo e Chevreuil: "a crítica não cria desalentos, não promove desânimos, [mas] estimula para as grandes obras artísticas", ao contrário - nos diz ele - de um Veríssimo, de um Araripe Jr., por exemplo. Da obra "insistente de combate e de negação" de José Veríssimo, Almáquio afirma que "resta uma pálida memória, a apagar-se dentro em pouco, pois a sua crítica, se não criou individualidades, não as desfez", do mesmo modo que de Araripe, segundo afirma, jamais "proveio um nome nacional".44

Na opinião de Almáquio Dinis, os críticos brasileiros, "os que têm passado pela função de julgar nas letras brasileiras", não têm cumprido esses requisitos. José Veríssimo - nos diz ele - "submetia os seus julgamentos a um método inteiramente invariável"; Sílvio Romero "fala apenas dos livros que o agradam, [revelando] um extremo cuidado pelas classificações e as doutrinas, de sorte que um conceito é sempre um dogma, a favor ou a contrário, para sempre".

\footnotetext{
42. Id., p 15.

43. Id., p. 18.

44. Id., pp. 19-22.
} 
Isso, entretanto, não o impede de reconhecer que em Romero se concentrava o melhor legado crítico do período, fruto de um trabalho "verdadeiramente erudito - assinala de alguém que "compreendendo o valor social da crítica, tornou em astros figuras que perdurarão luminosas, tanto quanto a sua própria, na constelação das nossas letras".

Pena que logo adiante desfigure o que parecia uma resenha sensata, para alinhar na mesma escala de valores nomes como o de um Artur Orlando, um Tobias Barreto ou um Clóvis Bevilacqua. E pior, para incluir-se a si mesmo, sem o menor constrangimento, na tribuna dos melhores críticos de seu tempo. É o que nos diz quando afirma que "de uma feita, Vinício da Veiga [...] colocou-nos, a mim, a Miguel Melo e a Alcides Maia, sob o pontificado de Sílvio Romero, à testa dos nossos melhores críticos. E não há muito - ajunta - Cursino Silva, que começava a criticar, dizia, num de seus apreciáveis escritos, ser eu, dentro em breve, o crítico de maior valor no Brasil". ${ }^{45}$

Com tudo isso, é preciso levar em conta que, no conjunto exacerbado de tais excessos, Almáquio não deixa de, por vezes, apaziguar-se consigo mesmo para refletir em aspectos ponderáveis da atividade crítica. Estão neste caso algumas observações isoladas que, entretanto, não deixam de repercutir na contramão de suas suposições delirantes. Uma delas é a de que o crítico não deve transformar o seu trabalho na "arte de gozar os livros e de enriquecer", mas na tarefa de "aguçar", através deles, as suas próprias sensações de leitura, coisa que, a seu ver, ele só consegue, em primeiro lugar, sentindo a realidade da vida, antes de sentir-se a si mesmo; e, em seguida, ajustando a ela as sensações mais fundas que o belo nos oferece "quando objetivado em uma obra de arte". ${ }^{46}$ Isso o impedirá - argumenta - de reduzir as suas análises a "uma preferência pessoal imobilizada" e fora de contexto, como ocorreu algumas vezes com Araripe Júnior, em particular no caso do ensaio sobre Ibsen, citado por Almáquio.

Outra coisa é que, tendo recusado a crítica naturalista, de quem, como vimos, sempre reclamou "o legado de uma filosofia", não chegou a fechar inteiramente as portas às "promessas atuais" de críticos como Ronald de Carvalho e Tristão de Athayde em suas tentativas para construí-lo. É bem verdade que, ao falar de Afonso Celso, lembrou que apenas duas obras se firmaram a partir de sua influência positiva:

45. Id., pp. 22-5.

46. Id., p.26. 
"a Rosa mística, de Júlio Afrânio, e o Sê bendita! (1905), de minha lavra". ${ }^{47}$ Isto para não mencionar o modo definitivo como nos garante ter sido ele, Almáquio, quem orientou o trabalho do escritor Coelho Neto ("indiquei-lhe a rota melhor a seguir") na preparação dos seus Contos escolhidos; e a imodéstia com que elegeu a si mesmo como parceiro de Gonzaga Duque na vanguarda da nossa prosa finissecular, ao situar um de seus livros (Raio de sol, 1903) ao lado de Mocidade morta, "um dos raros romances simbolistas da crise nacional" 48

Mesmo assim, andou perto de ser um crítico quando soube distinguir, ainda que em livros de poetas inexpressivos, como Magalhães de Azeredo (Quase parábola, Horas sagradas) e o próprio Coelho Neto (Procelárias), a originalidade "nos versos de 13 e 15 sílabas, não rimados, ao gosto de Carducci, D'Anunzzio e Tommaseo", um gosto que, segundo Almáquio, nos revelava a importância dos versos brancos, contra o preconceito de que os versos sem rima eram como incompletos ou um meio termo entre a poesia e a prosa. ${ }^{49} \mathrm{Ou}$ mesmo quando soube aplicar a figura aristotélica da catarse à "literatura defensiva" de Monteiro Lobato, em livros como Urupês e sobretudo Negrinha, nos quais "os desdobramentos dos perigosos dados da realidade mais crua - como observa - se transformam em motivos literários, [...] alertando os homens para o conhecimento dos males que possam aniquilá-10.". ${ }^{\circ}$

De igual modo, soube ver na extração decadentista dos contos e crônicas de João do Rio um decalque quase linear do mundo parisiense, relativizando o seu alcance no âmbito da "cultura formativa da nossa vida social". ${ }^{51}$ Além disso, ao reconhecer "a simultaneidade dos estilos literários", soube estender aos decadentistas de seu tempo a impressão estilística de que "Paul Bourget cruza com Stendhal e Pompeyo Gener",

\footnotetext{
47. DINIS, Almáquio. Da estética na literatura comparada, op. cit., p. 89.

48. Id., pp. 110-1 e 124.

49. Id., p. 183

50. Id., p. 191.

51. Sua diferença com João do Rio vinha já de alguns anos, quando enfeixou em seu livro Sociologia e crítica (Porto: Magalhães \& Moura, 1910) o capítulo "Versus Paulo Barreto", no qual, depois de considerar a este último "um indigesto smart da imprensa do Rio e charlatão pernóstico, cheio de frases francesas e dichotes ingleses, mas oco de bons sentimentos e muito mais ainda de ideias que se possam aproveitar", Almáquio desdenha de seus escritos, interessados em "chamar de encantadora à alma de umas ruas que só têm urubus, mariposas de luxo, fomes negras, perversões e malandros, como o próprio sr. Paulo Barreto". Ver: Sociologia e crítica, op. cit., pp. 70-1.
} 
três tendências distintas que, vinculadas ao medanismo de Zola, dariam origem ao que chamava "O vulgarismo, o criminalismo e o pseudodarwinismo". ${ }^{2}$

Com esse espírito, aproximou a poesia de Augusto de Lima à dos parnasianos mais reconhecidos (Olavo Bilac e Alberto de Oliveira), sem deixar de insistir junto aos novos, na esteira de Theodore de Banville, para que lessem "o mais que lhes fosse possível, dicionários, enciclopédias, obras técnicas que tratem de todos os ofícios e de todas as ciências especiais; catálogos de bibliotecas e de livrarias, livrinhos de museus, enfim, todos os livros que possam aumentar o repertório das palavras que sabeis". Tudo isso, sem esquecer a advertência de Guyau, de que "levada ao extremo, a pesquisa da rima tende a fazer perder ao poeta o hábito de ligar logicamente as ideias, isto é, de pensar, porque pensar (sic), como disse Kant, é unir e ligar". ${ }^{53}$

Surpreendentemente, num tópico dedicado a Goulart de Andrade, Almáquio faz uma referencia à "função teatral belicosa", segundo ele "cheia de tendências novas e propensões estéticas" reveladoras, nomeando entre os seus principais representantes o dramaturgo alemão Frank Wedekind, que - conforme assinala - "antecedeu com as suas criações o futurismo de F. T. Marinetti, na parte relativa ao aproveitamento da velocidade universal como fonte de energias estéticas”. A indicação é importante porque, através dela, Almáquio estabelece uma comparação entre a dramaturgia de Wedekind e a estética futurista de Marinetti, que ele foi um dos primeiros, senão o primeiro, como mostrou Annatereza Fabris, ${ }^{54}$ a divulgar no Brasil. Diz Almáquio que

\footnotetext{
52. Id., pp. 215-23.

53. Id., pp. 266-7.
}

54. Annatereza Fabris, em artigo recente, destacou a importância de Almáquio Dinis, ao mostrar como foi ele, e não Oswald de Andrade em 1912, o responsável, como fazia crer a crônica do modernismo, pela importação do futurismo ao Brasil. Como revela a autora, foi Almáquio, em 30 de dezembro de 1909, pelas páginas do Jornal da Bahia ("Uma nova história literária"), quem primeiro - ainda que de modo discutível do ponto de vista crítico - traduziu do italiano e elaborou "uma história sucinta das repercussões internacionais" do Manifesto futurista de F. T. Marinetti, a que juntou algumas notas curiosas sobre a sua veia polêmica na literatura e fora dela, enriquecidas de trechos de uma entrevista do autor do L’aeroplano del papa. Mesmo ressalvando a figura contraditória do crítico baiano, Annatereza deixa claro que o artigo de Almáquio é mais relevante, da perspectiva histórico-literária, do que os dois outros que o precederam na divulgação do futurismo no Brasil: o do português Manuel de Souza Pinto, correspondente do Correio da Manhã, que deu a público a primeira notícia daquele movimento no Brasil, em crônica de 6 de abril de 1909; e a do jornalista Manuel Dantas, autor provável de uma tradução parcial do manifesto de Marinetti (continha apenas os onze pontos programáticos), que saiu em 5 de junho daquele 
"enquanto o futurismo é o anarquismo das literaturas, sendo, também, a arte do amor ao perigo, ao hábito da energia e da temeridade, da audácia e da revolta, a dramaturgia de Wedekind, no seu aspecto neoenergético, nas suas capacidades físicas, é a criação de uma reforma social, batendo-se contra a mania da verdade do naturalismo, mas em favor da verdade estética da alma humana".55

Outro de seus insights iluminadores foi ter percebido, na prosa de Mário Sette (Senhora de engenho), "em cujos cenários há sempre um raio de sol ou um foco de luz", que os estados de alma das personagens, "numa continuidade célere de emoções, lembram a indistinção dos estados sucessivos que caracterizam a mobilidade da consciência, na teoria de Bergson", mais precisamente em Matière et memoire, que ele cita com todos os protocolos: Paris, 8. ed., 1902, pp. 37 ss. A notação é curiosa porque sublinha, no romance, que, ao contraste entre o excesso de tempo consumido e a exiguidade do espaço figurado, corresponde uma espécie de impasse "para a percepção nítida da vertigem do tempo", fazendo com que a continuidade das cenas se dissolva na "ilusão de que pode haver uma realidade em que nada começa", inutilizando assim, em esferas contrapostas, a integração entre a "corrente da consciência" (mobilidade do eu) e a força da "natureza real". 56

O mesmo ocorre quando, escrevendo sobre a prosa de Depois da meia-noite, de Benjamim Costalat, Almáquio observa que "o estilo não compete com a concepção", de onde lhe vem a impressão de que, nesse autor, por mais esforços que ele faça, a obra sempre ficará parecendo inferior a seu talento. Nas palavras do próprio crítico, haverá "verdadeiramente um páreo, [em que] o fulgor das ideias é sacrificado pela enunciação, porque não é dado à escrita acompanhar a intensidade com que Costallat tem as suas visões intelectivas da arte". ${ }^{77} \mathrm{O}$ resultado, segundo ele, é que a "descontinuidade"

ano pela República de Natal. Uma das razões para isto, como esclarece a pesquisadora, é que - comparados com o escrito de Almáquio Dinis, tanto o texto de Souza Pinto quanto o de Dantas perdem longe em densidade; o do primeiro, por resumir-se a uma espécie de "provocação extravagante" como outra qualquer; e o de Dantas, por nos remeter apenas genericamente - nos diz ela - "a um movimento entusiástico e revolucionário, violento e incendiário", mas nada que vá além de mera curiosidade. Cf. FABRIS, Annatereza. "O futurismo como estética patológica: alguns aspectos de sua recepção no Brasil". Dossier Thématique: Brésil, questions sur le modernisme. In: Artelogie, n. 1, 2011.

55. Id., p. 295.

56. DINIs, Almáquio. A relatividade da crítica, op. cit., p. 25.

57. Id., p. 32. 
atropela o ritmo do livro, tornando irrealizável a simultaneidade da ideia com a sua expressão escrita, "criando a sensação de um tempo díspar". ${ }^{8}$

É verdade que há descaídas. Como a da leitura do poema "Era uma vez", de Guilherme de Almeida, ${ }^{59}$ em que Almáquio nos traz de volta a antiga obtusidade do "esteta científico" ainda obcecado - como nos mostra a nota de pé de página em que cita o matemático Sellien em alemão - em demonstrar o fato de que "a relatividade do começo é equipolente à relatividade do fim", o que a seu ver viria confirmar "a noção einsteiniana do universo finito, mas não limitado, contra o universo finito da teoria newtoniana".60 "É assim - conclui ele - com conhecimento a posteriori que se tornou, por hereditariedade natural, a priori, [que] Guilherme de Almeida compreendeu aquela vez especial de seus amores...."

Mas há coisas curiosas, como, por exemplo, o artigo em que as hipóteses de Tristão de Athayde sobre Afonso Arinos são comparadas às especulações de um "astrônomo que desse explicações do brilho das estrelas com as intuições de Tycho-Brahe"; ou como a observação de que, nos versos do poema "Música de câmara", de Ronald de Carvalho (Epigramas irônicos e sentimentais), ${ }^{61}$ "não há uma unidade lógica de relação entre o pingo de água e a andorinha, e a folha e a chuva. Todavia, tem-se uma visão intuitiva da unidade, pela sucessão rítmica dos múltiplos planos da criação" que a intuição do artista reelabora verbalmente sem levar em conta que "o pensamento verbal só se nutre dos convencionalismos". ${ }^{62}$ Isso explica, segundo Almáquio, que Ronald de Carvalho pode ser considerado um escritor, mas nunca será um grande poeta. ${ }^{63}$

E que dizer de seu diálogo com o narrador de Os condenados, de Oswald de Andrade, ao interrogar no livro a hipótese do refúgio schopenhaueriano da meditação contemplativa, para aderir ao "exercício condicionado da liberdade, na resistência oposta pelos instintos do homem ao constrangimento das brutalidades da luta pela vida"? Para

\footnotetext{
58. Id., p. 33 .

59. "Era uma vez... Mas eu não sei como, onde, quando,/ por que foi isso. Eu sei que ela estava dançando./ O jazz-band esgarçava o véu de uma doidice./ Ela olhou-me demais - e um amigo me disse:/ 'Cuidado! É sempre assim que essas coisas começam!'[...]". Id., p. 41.

6o. Id., pp. 42-3.

61. "Um pingo d'água escorre na vidraça./ Rápida, uma andorinha cruza no ar./ Uma folha perdida esvoaça, esvoaça.../ A chuva cai devagar.... Id., p. 67.

62. Id., pp. 67-8.

63. Id., pp. 69-70.
} 
Almáquio, estaria aí a grande contribuição do romance - uma obra em que, a seu ver, está enfeixada a demonstração de que, "embora a metafísica não o queira, o êxtase dos sexos, separando as criaturas e dividindo almas, traça a origem dos mundos [...] como norma de ação, tanto na vida como na arte". É dela - a sexualidade enquanto poder que "resiste à serenidade das contemplações, para imprimir à obra de arte o cunho de sua própria personalidade" - que vem, segundo Almáquio, a grandeza do livro de Oswald de Andrade. ${ }^{64}$

Mas afinal, diante de tanta controvérsia nesse imenso cipoal de contradições, a verdade é que concluímos por não haver distinguido - por mais que o tentássemos - uma direção de leitura para a obra crítica de Almáquio Dinis. Ele mesmo parece não haver se encontrado em meio a tantas "influências" que afirma ter recebido: D’Anunzzio, Maeterlinck, Nietszche, Baudelaire, Edgar Poe, Villiers de Lisle Adam, Barbey d'Aureville, Huysmans, Barrès, Wilde, Ruskin, Zola, Eugênio de Castro, sem falar nos "prógronos" dos clássicos, dos românticos, da crítica naturalista (Sílvio Romero à frente), e mais Taine, e Bourget, e Anatole France, e Verhaeren, e Bouhélier, e Le Blond, e Einstein, e Minkowski, e Newton, mas também Brunetière, Lanson — todos, sem exceção, nos diz ele, responsáveis pelo "meu evolucionismo na carreira das letras, [fazendo] palpitar em mim o desejo de renovar-me sempre". ${ }^{65}$

Não esqueçamos, a propósito, que ele mesmo se encarregou de anotar e divulgar em seu livro os elogios, que sempre cultivou, ao aproximar-se dos escritores famosos do seu tempo. Max Nordau, por exemplo, agradecendo a remessa do ensaio Da estética em literatura comparada, comparece nos seus registros dizendo que Almáquio se movia "sur le terrain le plus solide en rattachant les lois de la esthétique aux lois générales de la nature"; Philéas Lebesgue também aparece prometendo a um Almáquio embevecido analisar proximamente "le curieux livre de critique portugaise (sic) d'Almachio Diniz, A perpetua metrópole", pelas páginas do Mercure de France; e o próprio Anatole France, para a glória suprema do nosso crítico, depois de ler a resenha de Almáquio sobre as mulheres do Barba Azul, escreveu-lhe de próprio punho para dizer-lhe que "larticle, que je viens de lire, me flatte et me touche profondement". ${ }^{66}$

64. Id., pp. 83-4.

65. DINIs, Almáquio. Zoilos e estetas (figuras literárias), op. cit., pp. 71-84.

66. Id., pp. 28,29 e 38. 
Isto tudo sem esquecer que Sílvio Romero o chamou de "notável polígrafo nacional" e o próprio José Veríssimo, tantas vezes descomposto por ele, reconheceu, nele, por carta, "um autor cheio de talento". Tudo, aliás, conforme os protocolos da convivência intelectual civilizada em que o elogio quase nunca significa o que parece afirmar.

Almáquio precisava acreditar nos encômios que lhe faziam e, certamente, morreu convencido de haver cumprido o papel de um grande crítico.

Antonio Arnoni Prado é professor de Literatura Brasileira da Universidade Estadual de Campinas. Autor, entre outras obras, dos livros Trincheira, palco e letras: crítica, literatura e utopia no Brasil (Cosac Naify, 2004), Itinerário de uma falsa vanguarda (Editora 34, 2010), Lima Barreto: uma autobiografia literária (Editora 34, 2012) e Dois letrados e o Brasil nação (Editora 34, 2015), foi o organizador da edição da crítica literária dispersa de Sérgio Buarque de Holanda nos dois volumes de O espírito e a letra (Companhia das Letras, 1996). 